\title{
Improving public sector knowledge sharing through communities of practice
}

\author{
Jørgensen, Rasmus; Edwards, Kasper; Scarso, Enrico; Ipsen, Christine
}

Published in:

VINE Journal of Information and Knowledge Management Systems

Link to article, DOI:

10.1108/vjikms-08-2019-0115

Publication date:

2021

Document Version

Peer reviewed version

Link back to DTU Orbit

Citation (APA):

Jørgensen, R., Edwards, K., Scarso, E., \& Ipsen, C. (2021). Improving public sector knowledge sharing through communities of practice. VINE Journal of Information and Knowledge Management Systems, 51(2), 318-332. https://doi.org/10.1108/vjikms-08-2019-0115

\section{General rights}

Copyright and moral rights for the publications made accessible in the public portal are retained by the authors and/or other copyright owners and it is a condition of accessing publications that users recognise and abide by the legal requirements associated with these rights.

- Users may download and print one copy of any publication from the public portal for the purpose of private study or research.

- You may not further distribute the material or use it for any profit-making activity or commercial gain

- You may freely distribute the URL identifying the publication in the public portal 
Title: Improving public sector knowledge sharing through communities of practice

\section{STRUCTURED ABSTRACT}

Purpose: This paper studies the impact of intentionally developed communities of practice (CoPs) on knowledge sharing and practice improvement in an administrative public sector organisation (PSO).

Design/methodology/approach: A case study approach was utilised to analyse the impact of the CoPs intentionally developed by four different teams at a Danish PSO. The study applied a CoP development framework suggested by the literature to develop the CoPs.

Findings: Three out of the four CoPs were successfully developed, and they positively affected knowledge sharing and practice improvement. CoP participants engaged in conversations to explore individual ways of working, share knowledge and ultimately improve practice.

Standardisation and boundary spanning were identified as contextual PSO factors influencing the CoP activities.

Research limitations/implications: The findings verify the framework and contribute to a better understanding of the factors affecting the development of CoPs that positively impact knowledge sharing and practice improvements in a PSO context.

Practical implications: The study provides operations managers in PSOs with a framework for developing CoPs to improve work performance through better knowledge sharing among employees.

Originality/value: The paper provides case study evidence for the relevance of CoPs in PSO settings and highlights the necessity of investing resources in employee knowledge-sharing interactions.

Keywords - Community of practice, CoP, Knowledge sharing, Public sector organisations, Practice improvement

Paper type - Research paper 


\section{Introduction}

Knowledge sharing among employees is important for the productivity of public sector organisations (PSOs) (Amayah, 2013; Hislop, 2013; Mc Evoy et al., 2019), but there is limited research on the topic, particularly in comparison with the private sector (Massaro et al., 2015; Sandhu et al., 2011). We do know, however, that collaborative practices characterised by trust and interactions can facilitate the sharing of knowledge in PSOs, especially of the tacit knowledge component (Jarvie and Stewart, 2018; Amayah, 2013; Gillani et al., 2018, Salleh et al., 2013).

A community of practice (CoP) is a powerful and widespread collaborative process that supports knowledge sharing and practice improvements (Aljuwaiber, 2016). A CoP is characterised by rich conversations and mutual exchange of practice-rooted knowledge (Agrifoglio, 2015; Akhavan et al., 2015), which facilitate the development of a socially embedded joint practice (Orr, 1996; Wenger et al., 2002; Pyrko et al., 2017). CoPs are formed by a 'group of people who share a concern, a set of problems, or a passion about a topic, and who deepen their knowledge and expertise in this area by interacting on an ongoing basis' (Wenger et al., 2002, p. 128). A fundamental element of a CoP is participants thinking together, i.e., engaging in collaborative exploration of experiences and practice development (Pyrko et al., 2017).

While CoPs were initially regarded as a self-organising emergent phenomenon (Lave and Wenger, 1991; Li et al., 2009), there is mounting evidence that they can be intentionally developed (Chu, 2016; laquinto et al., 2011; Ng and Ang, 2007; Jassbi et al., 2015) to support knowledge sharing both in a business (Aljuwaiber, 2016) and public (Amayah, 2013) context. However, empirical evidence about the impact of intentional CoP development in PSOs remains insufficient, especially when compared with the private sector (Sallán et al., 2012; Blunk and Prilla, 2017; Pee and Kankanhalli, 2016; Akhavan et al., 2015). Also, there is little evidence about how PSOs' contextual factors (i.e., organisational variables) shape CoPs (Jassbi et al., 2015).

The purpose of this study is to analyse the impact on knowledge sharing and practice improvement of four CoPs intentionally developed by applying a research-based framework within a Danish PSO. The study also investigates the contextual factors that affect CoP development and functioning.

\section{Theoretical background}

\subsection{Collaborative practices and CoPs}

The literature clearly demonstrates that the development of organisational knowledge is crucial for improving PSO services (Bate and Robert, 2002; Nutley et al., 2002; Massaro et al., 2015; Mc Evoy et al., 2019). In this context, collaborative practices are critical for efficient use of knowledge, people and processes to improve performance (Jarvie and Stewart, 2018). Indeed, the adoption and use of collaborative practices, particularly CoPs, support sharing and development of practiceembedded knowledge (Amayah, 2013; Diamond and Rush, 2012). 
The notion of the CoP was introduced almost 30 years ago by Lave and Wenger (1991) as part of a broader conceptual framework for reflecting on learning in its social dimension. Since then, this notion has gained increasing popularity and found extensive use in many private and public contexts (Wenger, 2010).

The study of CoPs originates from different epistemic understandings. Descriptive studies (e.g., Gau, 2013; Gabbay and le May, 2004; Cirella et al., 2018; Lave and Wenger, 1991) have approached CoPs as an emergent and self-organising phenomenon. Conversely, studies with a prescriptive perspective (e.g., laquinto et al., 2011; Ng and Ang, 2007; Pyrko et al., 2017) have approached CoPs as arrangements that can be deliberately developed to support organisations. Following this latter perspective, explanatory frameworks have been proposed to shed light on the factors that are critical for CoP development. For instance, Scarso et al. (2009) affirmed that the successful development of a CoP is based on four pillars - organisational, cognitive, economic and technological - that need to be adequately and consistently planned. Gongla and Rizzuto (2001) elaborated a CoP maturity model, which they proposed as a road map for evolving a CoP from the potential stage to the active one.

Other frameworks have underlined connections between CoP processes and organisational processes (McKellar et al., 2014) and emphasised the alignment between CoP development and the organisational context (Jassbi et al., 2015). Specifically, CoP development is influenced by the level of formality, geographical dispersion of participants and centralisation (Jassbi et al., 2015). If CoP participants have a high geographical dispersion, CoP development initiatives must take into account how interactions and discussions can take place without relying solely on physical meetings, e.g., by integrating information and communications technology (ICT) solutions that provide connectivity (Nithithanatchinnapat et al., 2016). To sum up, there is still no single theoretical framework that explains and can be used as a guide for CoP development and management, which was also noted in the literature review by Bolisani and Scarso (2014).

\subsection{Impact of COPs on PSOs}

In recent years, worldwide CoPs have been introduced in the public sectors of various countries and contexts, as illustrated by the following examples. The British National Health Service initiated intentional development of two CoPs to improve knowledge sharing among care personnel; one CoP struggled and the other was successful (Pyrko et al., 2017). In the successful CoP, participants shared knowledge and developed their practice. The behaviour was characterised by two distinct features: interlocked indwelling and sharing of tacit knowledge, which are fundamental for the central CoP activity of thinking together. Participants actually thinking together is what brings a CoP to life and what CoP development should aim for, as opposed to naming something a CoP and expecting thinking together to occur as an outcome.

In Hong Kong secondary schools, CoPs were developed to implement knowledge management (KM) (Chu, 2016). In particular, CoPs were developed as an interaction-based approach to 
supplement an information-based approach to KM (Hansen et al., 1999; Chu, 2016). Teachers joined the CoPs to share knowledge and reported that CoP participation resulted in them reflecting upon individual ways of working, sharing knowledge and gaining practical knowledge from peers.

In a Taiwanese PSO, employees with interdependent tasks interacted in a CoP, which resulted in mutual learning and led to the development of shared practices (Gau, 2013). The CoP was developed as official business to bring together employees who shared similar interests, and the CoP's informal and relaxed atmosphere was conducive for sharing knowledge and developing a shared practice.

Finally, in the U.S., a state agency organisationally instituted a CoP and individual network to support the integration of new employees (Hatmaker et al., 2011). Both the CoP and individual network contributed to individual information acquisition and learning; however, the network compensated for the minimal effect of the CoP, which, in that case, was described as similar to a training event (Hatmaker et al., 2011, p. 409).

There are several examples of CoPs developed by PSOs operating in different sectors (e.g., education, public services and especially healthcare) and with various aims (e.g., sharing experiences, developing shared practices and integrating new employees). However, empirical investigation of the impact of intentionally developed CoPs in the public sector is still limited compared to the private sector (Iaquinto et al., 2011; Pee and Kankanhalli, 2016; Blunk and Prilla, 2017).

Moreover, there is evidence that what is already known about CoPs in the private sector cannot simply be replicated for CoPs in the public sector (Bolisani et al., 2016; Blunk and Prilla, 2017). In particular, several challenges distinguish the public and private sectors. Public organisations face difficulties in expressing their goals clearly. Additionally, public employees tend to see knowledge as private, since it is viewed as closely associated with power (Seba and Rowley, 2010). Amayah (2013) confirmed that organisational goals in public organisations are generally more difficult to measure and more conflicting than in private organisations, and they are affected by political influences. Gau (2013) stated that in public organisations, specific labour divisions can act as disincentives for knowledge sharing. Furthermore, the public sector is not a single organisation but rather is highly diverse, and thus, CoP development and functioning can vary according to some specific contextual factors that characterise the organisational setting in which it takes place (Massaro et al., 2015).

The literature about public CoPs is still underdeveloped, and there is a need for further studies that focus on this topic. This paper contributes to filling this research gap by analysing and discussing employees' experiences with a PSO in which a framework for intentional CoP development was applied. In particular, the study offers further empirical evidence about how intentionally established CoPs can contribute to knowledge sharing and practice development in a 
PSO setting. In addition, it intends to verify if (and how) CoP development can be affected by the presence of some factors that are specific to the application context.

\section{Research questions and approach}

The study applied a framework for intentional CoP development recently proposed in the literature (Author details hidden) in a Danish PSO, the Danish Tax Administration (SKAT), to analyse how intentionally developed CoPs impact knowledge sharing and practice improvement. Two research questions shaped the focus of the study:

- RQ1: How do intentionally developed CoPs impact knowledge sharing and practice improvement in an administrative PSO setting?

- RQ2: What specific contextual factors shape CoP activity and influence CoP outcomes in an administrative PSO setting?

To answer the research questions, we applied a case study method since it is best suited to the investigation of a contemporary real-life phenomenon in a specific context and allows for the discovery of explanatory answers to how and why events occur (Yin, 2017). Specifically, we performed a longitudinal study lasting 70 weeks in total aimed at analysing the whole process from developing a CoP to capturing the resulting changes in knowledge sharing and practice improvement (Yin, 2017).

The investigated case concerned a unit of the SKAT comprised of four teams; within each team, a CoP was intentionally developed by applying the framework illustrated in Figure 1 . This allowed us to analyse and compare four different CoP development initiatives carried out inside the same organisations. The investigated unit, MOTOR, is a relevant PSO case given that legislation and written guidelines frame how the work is done and because their way of working and contacting clients is typical of other administrative PSO units. The investigated unit had not previously considered or promoted CoP-like activities.

\subsection{Case context}

SKAT is a public organisation responsible for taxation in Denmark, which employed approximately 7000 people in 2016. During the research project, SKAT underwent a major transformation, and the description of the organisation here refers to its state in 2016-2017. SKAT is organised under the Danish Ministry of Taxation and divided into functional areas such as salary tax, company tax, VAT, etc. The unit participating in the study belongs to the automation division, MOTOR, which is responsible for taxation related to selling, buying and owning a motor vehicle. MOTOR has offices near most major cities, and several of its functions are available at all locations. Four teams from MOTOR participated: Export (31 employees), Import (24 employees), Visitation (23 employees) and Pricing (nine employees). 
The work in MOTOR takes place in normal office settings where employees share large or small office spaces and have their own desks, personal computers (PCs) and telephones. The employees are in frequent contact with vehicle owners, and occasionally they discuss special or difficult cases either face-to-face or using ICTs (e.g., Skype, email or telephone). MOTOR has written guidelines prescribing how a task must be completed, which are available on a server accessible from the employees' PCs.

\subsection{Intentionally developing CoPs}

CoPs in MOTOR were developed by applying a framework specific to CoP development within operations, which was recently proposed in the literature (Figure 1) (Author details hidden). The framework was developed on the basis of seven critical factors for CoP development that inform six sequential steps. These factors, identified from an analysis of the relevant literature, are voluntary participation, coordination of activities, allocation of time, allocation of a meeting space, knowledge responsibility, choosing an ICT and a soft approach. A prerequisite for using the framework is the presence of a CoP promoter (e.g., a senior manager or consultant), and the framework adopts the perspective of the promoter seeking to develop a CoP.

\begin{tabular}{|c|}
\hline STEP 1- Manager introduction \\
\hline Participants: CoP promoter and manager \\
\hline \\
STEP 2 - Practice definition \\
\hline Participants: Manager \\
\hline \\
\hline STEP 3 - Coordinator identification \\
\hline Participants: Manager and employees \\
\hline STEP 4 - Invitation to participate \\
\hline Participants: Manager and employees \\
\hline STEP 5 - Facilitated start-up workshop \\
\hline Participants: CoP promoter and volunteer employees \\
\hline STEP 6 - Manager communication \\
\hline Participants: CoP coordinator \\
\hline
\end{tabular}

Figure 1 - The six steps of the framework for intentional CoP development (Author details hidden).

In Step 1 (manager introduction), the manager is informed by a CoP promoter about what a CoP is in relation to workplace knowledge sharing and new knowledge creation, CoP management, resource allocation, and the necessity of allocating the CoP decision-making authority in developing the practice. In Step $\mathbf{2}$ (practice definition), the manager identifies a practice to which management will dedicate resources to develop a CoP. There are two criteria. First, a practice is a collection of tasks, which can be identified as a complete job. Second, the goal is to choose a CoP topic (Wenger et al., 2002), in which a sub-group of employees share a common interest. In Step 3 
(coordinator identification), a coordinator is identified among possible CoP participants and asked by the manager if he/she is interested in acting as coordinator. The coordinator must have extensive practice experience and must volunteer to be a coordinator. The coordinator's tasks are to arrange meetings, manage new knowledge and improvements and communicate with stakeholders. In Step $\mathbf{4}$ (invitation to participate), an invitation is extended to employees via the organisation's preferred communication method. Participation must be voluntary to ensure effective management of knowledge resources (Amayah, 2013). Participation entails two explicit requirements - an interest in sharing knowledge about the practice and experience with the practice - with the purpose of attracting employees who will be active and participate with an open mind in conversations (Wenger et al., 2002). In Step 5 (facilitated start-up workshop), the employees who expressed an interest in participating are gathered for a start-up workshop facilitated by the CoP promoter. The participants are told that the purpose of the CoP is to voluntarily share knowledge through conversations to improve a specific practice (defined in Step 2). The workshop participants are given two questions to discuss in plenum: How and why are we relevant to one another in this group? and What are we going to do? The participants discuss, agree on and inform the manager about a suitable meeting room, what resources they need (including the necessary ICT) and a CoP time schedule. In Step 6 (management communication), the coordinator is asked to write minutes for each CoP meeting and email them to the manager sponsoring the CoP and the participants. The purpose of this activity is to keep the sponsor and participants involved, particularly the manager, who must continuously allocate resources to the CoP.

With one of the researchers (first author) acting as a CoP promoter, the study applied the framework to develop a CoP within each of the MOTOR teams in order to improve knowledge sharing and practices. This paper's result and discussion section describe and analyse how three CoPs were successful while the fourth one was unsuccessful. The following sections also illustrate the impact of CoP activities as well as the contextual factors that shaped such activities on knowledge sharing and practice improvement.

\subsection{Research method}

As previously described, the study lasted 70 weeks and was comprised of an intervention period spanning 18 weeks, a subsequent study period of approximately 26 weeks, and a post-study follow-up of approximately 26 weeks (see Figure 2). The two periods of 26 weeks were chosen to assess both the apparent immediate impact of the framework's application as well as the longterm impact. To assess changes (impact) in knowledge sharing and practice, a baseline to followup study was chosen. The baseline data collection consisted of documenting the old guidelines. Follow-up consisted of documenting the new guidelines, coordinating effect modifier assessment (EMA) workshops (Edwards and Winkel, 2018), conducting CoP coordinator interviews, and collecting minutes from CoP meetings. 
The collected guidelines allowed for a simple comparison to determine changes in practice. The EMA workshops (one per team) were used to develop a timeline of events and changes in work and practice, which allowed for the identification of contextual factors. This was supported by coordinator interviews and minutes.

The long-term CoP activity was assessed with post-study follow-up emails sent to the CoP coordinators. Because the teams perform similar tasks and are organised in a similar fashion, the study design became a single case study with four embedded units (Yin, 2017). Moreover, because the CoP development process was similar for each team, a repetitive logic was present, making it possible to generalise across the four teams (Yin, 2017).

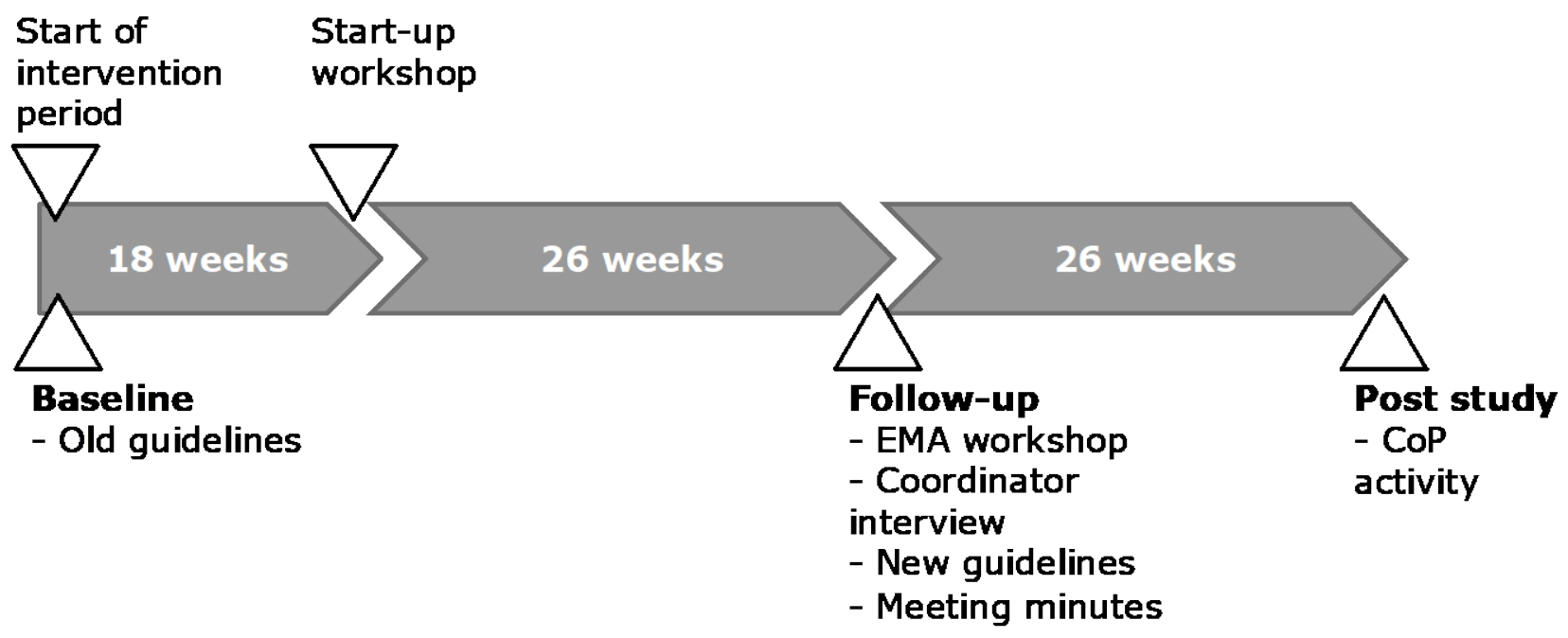

Figure $\mathbf{2}$ - The timeline of the study, including the intervention period and the study period.

The way tasks are executed in SKAT is similar to other kinds of case work (e.g., applying for benefits). This makes SKAT a relevant case because it is characteristic of common PSO casework (Yin, 2017; Bryman and Bell, 2011). Thus, the study results have potential value for similar PSOs.

\subsection{Data collection and analysis}

The case was analysed and discussed by drawing information from five different sources, as described below.

\subsubsection{Meeting minutes}

The minutes of the CoP meetings, which were written by CoP coordinators, were emailed to the researchers. Analysis of the meeting minutes was used to document the CoP activity. These minutes helped us to keep track of the CoP development process as well as to identify particularly noteworthy meeting activities. 


\subsubsection{Guidelines versions}

Old and revised versions of the written guidelines were emailed to the researchers by the coordinators and were compared to evaluate how knowledge sharing in the CoP improved practice. The guidelines were used to characterise and document the outcomes of CoP meetings and changes to how work was performed.

\subsubsection{EMA workshops}

The EMA workshops identified the events that influenced and changed work practice during the 26-week study period and evaluated how the events modified the study results (Edwards and Winkel, 2018). Events were classified as CoP related (i.e., events related to the intentionally developed ( $O P$ ) and context related (i.e., all other events). This allowed for isolation of the CoP's impact on knowledge sharing and practice improvement from other organisational changes and processes. Each workshop was recorded, transcribed, codified, categorised and themed. The initial codification was done to transform workshop transcripts into segments of data. The codification of the transcripts was done using structural codification, which is particularly relevant for semistructured data-gathering protocols in which a specific research question is being explored (Saldaña, 2016). To aggregate the coded data from the initial codification into meaningful categories and homogenous units of analysis, pattern codification was applied (Saldaña, 2016). Finally, themes were identified through analytical reflection drawing on theory to describe the subtle and tacit processes involved in CoP development and knowledge sharing (Saldaña, 2016).

\subsubsection{Telephone interviews with coordinators}

In telephone interviews with each CoP coordinator, findings from the EMA workshops and the identified guideline changes were discussed and qualified.

\subsubsection{Follow-up emails to coordinators}

The CoP coordinators were requested via email to inform the researchers about the CoP activities 26 weeks after the EMA workshop. The emails were used to document CoP activities in the latter 26-week period and assess the long-term impact of the framework.

\section{Results}

\subsection{CoP activity}

For all four teams, CoP activities took place throughout the 26-week study period (see Table 1). The Import CoP held five meetings in the first part of the study period and then abruptly stopped both meetings and activities. Export and Pricing held four meetings during the study period, which continued after the study period. Visitation held six meetings during the study period, and after the study period, they continued their work but did not hold any more meetings. In total, three out of four CoPs (Export, Pricing and Visitation) were successfully developed and 1 CoP (Import) 
failed to sustain their activity. The EMA workshops allowed us to identify the three main reasons behind the Import CoP failure: a change in coordinator, massive caseload and software update. First, because of a reorganisation, the coordinator was assigned a new role, but a successor was not identified. Thus, the functions of the coordinator were not performed. Hence, the CoP participants were not invited to meetings, and all activities ceased. Second, legislative changes resulted in an inordinate number of car deals, causing a backlog of cases at the Import unit, which left little time for CoP activity.

Table 1 - CoP activity during the study period

\begin{tabular}{|c|c|c|c|c|}
\hline \multirow[t]{2}{*}{ Team } & \multicolumn{2}{|c|}{ CoP Meetings } & \multirow[t]{2}{*}{ Participants } & \multirow[t]{2}{*}{ Years of Seniority } \\
\hline & Study Period & $\begin{array}{l}\text { After EMA } \\
\text { Workshop }\end{array}$ & & \\
\hline \multirow[t]{4}{*}{ Import } & \multirow[t]{4}{*}{5 meetings } & \multirow[t]{4}{*}{ No activity } & P1 & +10 \\
\hline & & & $\mathrm{P} 2$ & +20 \\
\hline & & & P3 & +2 \\
\hline & & & P4 & $<1$ \\
\hline \multirow[t]{3}{*}{ Export } & \multirow[t]{3}{*}{4 meetings } & \multirow[t]{3}{*}{3 meetings } & P5 & +20 \\
\hline & & & P6 & +20 \\
\hline & & & P7 & +1 \\
\hline \multirow[t]{3}{*}{ Pricing } & \multirow[t]{3}{*}{4 meetings } & \multirow[t]{3}{*}{6 meetings } & P8 & +2 \\
\hline & & & P9 & +20 \\
\hline & & & P10 & +20 \\
\hline \multirow[t]{4}{*}{ Visitation } & \multirow[t]{4}{*}{6 meetings } & \multirow{4}{*}{$\begin{array}{l}0 \text { meetings, } \\
\text { sustained } \\
\text { communi- } \\
\text { cation }\end{array}$} & P11 & +20 \\
\hline & & & P12 & +20 \\
\hline & & & P13 & $<1$ \\
\hline & & & P14 & +20 \\
\hline
\end{tabular}

Participants in the EMA workshops were asked if the CoP activity was different from their normal daily activity. The participants confirmed this and explained that the CoP facilitated conversations 
they did not have previously and that the conversations made it possible to identify differences in how tasks were done: 'If we had just worked two and two and done our job, it would probably never have come up' (P8). P6 testified that rich conversations took place within the CoP: 'We have conversations where we go through every little detail'. Other participants highlighted that the CoP offered time and space for having focussed conversations: 'Yes, it is [different]. We only have focus on one thing' (P5) and 'We are very focused when we are together' (P14).

To sum up, the EMA workshops confirmed that participants considered the framework to be an effective tool that supported the successful development of a CoP inside their organisation. The outcomes obtained from the CoP activities, and the contextual factors that affected such activities, are presented in the following sections.

\subsection{Knowledge sharing and practice improvements}

The CoPs facilitated knowledge sharing and discussions of how to improve practice. An example of this was captured during the EMA workshops:

- 'We discussed how we work and how we should work' (P1).

- 'We explored differences' (P8).

- 'We got a new perspective on old habits' (P7).

- 'It [the CoP] made you reflect on your own practice' (P10).

The next two examples provide evidence about how knowledge was shared and practices were improved.

\subsubsection{Example 1: CutePDF}

During a conversation in the Pricing CoP, the participants discovered that they all had different ways of performing the same task. The purpose of the task was to move information from one system to another by creating a PDF file and attaching it to a case. The participants shared their individual ways of working and had a collective discussion about the reasons for doing so and the pros and cons. They ultimately defined one best way of completing the task. The three approaches were as follows (see Figure 3).

P8 completed the task by saving the file (e.g., Word file) to his PC, printing a physical copy, scanning the physical copy and emailing it to himself in PDF format, saving the individual PDF files to his PC, and then attaching the files individually to the case. P9 saved each Word file to the PC, opened the files and converted them to PDF, and then attached the files individually to the case. P10 saved the files directly as PDFs to her PC using the program CutePDF and then attached the PDFs to the case as a bundle in one upload. The participants agreed that P10's approach was the smartest and improved the practice; the guidelines were subsequently updated accordingly. This example illustrates the CoP as a collaborative practice of thinking together (Pyrko et al., 2017). 


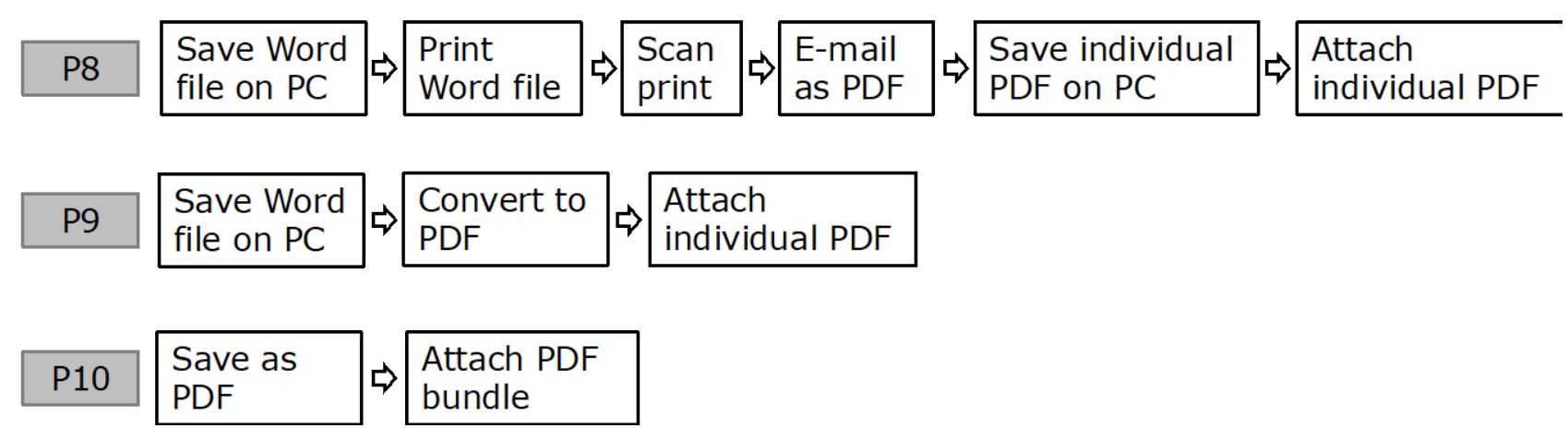

Figure 3 - The three approaches used by the individual participants.

\subsubsection{Example 2: Secure or not(e) secure}

The Danish Public Records Act specifies how information is to be stored and, in particular, whether the stored information may later be altered or deleted. During a discussion of a work procedure in the Export CoP, the participants realised that they had different ways of storing similar information they received from citizens. For example, some wrote a note in WordPad or Word and then attached the file to the case, and others used the note application in the case system. The participants found that using Word is not a secure format, while the note application is secure, and this was followed by a discussion about the legislatively correct method. The participants shared, explored and reflected upon their different ways of working, but they could not reach a decision. The participants consulted the Public Records Act without finding a solution. Ultimately, they consulted their manager, who is responsible for securing information in the correct format. The manager advised that the information should be stored in the secure system because this information is central to a decision that has financial consequences for citizens.

\subsection{Contextual factors shaping CoP activities}

The results of the EMA workshops allowed us to identify two main contextual factors that shape CoP activities in connection with the public context. The first was standardisation; with legislation comes the requirement of standardisation to ensure equal and lawful treatment of citizens. Standardisation framed the CoP conversations because the participants focussed on identifying one collectively agreed upon way of working. The second was boundary spanning; in some cases, participants lacked the knowledge or decision-making competence to decide how to do a task. Thus, the CoP would initiate boundary spanning and refer to legislation or the manager.

\subsubsection{The role of standardisation in shaping conversations}

Conversations in the CoP were framed by the requirement of task standardisation, which is a core value when working with regulation because all citizens must be treated equally and lawfully. The standardisation requirement framed the CoP conversations and was introduced by the participants, who stressed the need to define one way of performing a task. P11 stated, 'We had to agree. We had to find one way of doing it' because 'we have to treat customers equally'. This 
quote was from Example 2, in which the participants discussed and searched for the legislatively correct way of doing something. The second reason indicated by several participants was to reduce frustration. Participants noted that standardisation reduces frustration that arises from being told different ways of doing the same task. For example, this can occur when transitioning from Import to Export or when an employee is new. As P3 asserted, 'I chose to participate because the new people that come to SKAT should have a better start than I had. My training was 1:1 and then I had to read incomprehensible guidelines'.

\subsubsection{Boundary spanning}

Employees who transgress disciplines and organisational structure are boundary spanners; they are an inherent part of intra-organisational collaborative practices (Diamond and Rush, 2012). Boundary spanning connects different worldviews, allows for knowledge sharing between CoPs (Wenger, 1998) and can improve the collaboration between different groups of employees in PSOs (Conklin et al., 2013). Example 2 provides an illustration of boundary spanning; the CoP participants first referred to the legislation and then to the manager, as they lacked the appropriate knowledge. Through boundary spanning, the knowledge base of the CoP is continuously developed, and decisions are validated through input from stakeholders or other CoPs (Wenger, 1998; Huysman, 2004).

\section{Discussion}

The purpose of this study was to analyse the impact of intentionally developed CoPs on knowledge sharing and practice improvement in a PSO context and to identify the contextual factors that shaped the CoP activities. The EMA workshops confirmed that the framework is a useful tool to support the successful development of a CoP in a PSO setting. This was commonly recognised by all CoP participants.

\subsection{CoPs' impact on knowledge sharing and practice improvement}

The results of the study allowed us to provide a positive answer to the first research question because the three successful CoPs provided beneficial outcomes regarding practice improvement. In particular, Examples 1 and 2 demonstrated that the participants engaged in conversations in which different ways of working were explored and contrasted, and ultimately the participants improved their own practices and updated the guidelines. The participants proved willing to share ineffective ways of working when confronted with an improved way of working; this type of uncomfortable knowledge sharing demonstrates a high level of trust between the participants (Gillani et al., 2018).

However, the impact beyond the CoP was not investigated, and consequently, the larger organisational impact remains unknown. Passively disseminating the new guideline through a server has limited impact on the behaviour of non-CoP participants (Grimshaw et al. 2005). One approach could be to consider the employees that did not participate in the CoP as peripheral 
participants (Lave and Wenger, 1991), resulting in a need for the CoP participants to interact with their colleagues. Still, a CoP offers opportunities for discussing and contrasting ideas and work practices in a manner that daily work generally does not allow. In this regard, it is important that the community members are provided time and a place to have conversations, exchange their knowledge and develop their practice.

\subsection{Contextual factors shaping CoP activity}

Regarding the second research question, we identified two contextual factors shaping CoP activity that were connected with the public nature of the investigated organisation: standardisation and boundary spanning. Standardisation is particular to regulated contexts, as in the investigated case, and it framed the CoP conversations to focus on collectively identifying one way of working. A contrasting perspective could be that CoP participants explored different ways of working to develop individual practices. This is acceptable in contexts in which standardisation is not a requirement, for example, for teachers (Chu, 2016) or tour guides (Akkerman et al., 2008). In contexts where standardisation is not a requirement, a conversation can be a source of individual inspiration, but in a regulated context (e.g., a public tax administration), the room for individual practices is limited because a task must be performed the same way each time. However, it is worth recalling that when the need to define one way of working is enforced too strictly in the $\mathrm{CoP}$, there is the risk of missing out on rich conversations whereby the participants think together (Pyrko et al., 2017) and collaborate (Diamond and Rush, 2012) to explore different perspectives. Thus, in regulated contexts, the start-up workshop could involve a discussion about the importance of having conversations that initially diverge to explore different ways of working and then converge to ensure standardisation.

Boundary spanning may be necessary if the CoP participants lack knowledge and must resort to external sources to improve their own knowledge base. Indeed, one risk of a CoP is the development of knowledge which is contrary to the organisation (if the CoP acts too autonomously). This risk can be mitigated by connecting the CoP with an expert (Huysman, 2004; Scarso et al., 2009). Boundary spanning could have a positive impact on the CoP in the long-term given the introduction of new knowledge and organisational alignment (Wenger et al., 2002; Huysman, 2004). However, boundary spanning could also have a negative impact if it results in limiting the autonomy of the CoP participants and thus decreasing personal motivation to participate (Wolf et al., 2011; Lesser and Storck, 2001). In PSOs, boundary spanning is important because employees must adhere to legislation, and thus, seeking knowledge outside of the CoP should be the coordinator's responsibility.

To sum up, CoPs in PSOs can be impacted by contextual factors in the form of organisational variables, and this impact can range from the overall CoP structure and choice of ICT (Jassbi et al. 2015) to how conversations take place in the CoP (as demonstrated in this study). Hence, 
awareness of the possible impact of contextual factors is crucial for the effective development of a CoP.

\subsection{CoPs in PSOs}

As the results demonstrate, the limited research on CoPs in PSOs should be expanded, particularly in PSO organisations like healthcare, tax administration or administration of benefits, which are characterised by employees who gain individual experience and must perform tasks in a standardised manner and according to the law. A reason for the limited proliferation of CoPs in PSOs could be that CoPs are inhibited by a strict management approach and goal setting, which has accompanied the adoption of new public management. Thus, CoPs are not considered relevant by many managers in PSOs.

\section{Conclusion}

Despite facilitating knowledge sharing and improving productivity within PSOs, the research on CoPs in administrative PSOs is still scarce. This research sought to develop this field by studying the impact of intentionally developed CoPs on knowledge sharing and practice improvement in an administrative PSO context. The study was conducted as a longitudinal case study of the SKAT, in which four CoPs were developed based on a framework for intentional CoP development.

Three out of the four CoPs were successful in maintaining activity and influencing knowledge sharing and practice improvement. The failure of the fourth CoP was determined to be the result of exceptional causes (i.e., a change of coordinator due to a complete organisational restructuring, overwhelming caseload and software update). Two crucial factors of CoP development, the lack of a coordinator and lack of time, impeded the framework outcome in terms of long-term CoP activity.

The findings of the study not only confirm that CoPs can be intentionally developed by a public organisation in order to improve its operations processes, but they also verify the framework and its individual steps for the intentional development of CoPs. The study also identified two contextual factors linked to the specific nature of a public organisation, which, in the investigated case, shaped CoP activity: standardisation and boundary spanning. The organisational requirement of task standardisation impacted the CoP conversations, as employees considered it necessary to define one best way of working. Boundary spanning occurred when the CoP lacked knowledge, prompting the need to consult external sources (the manager and legislation), thereby expanding the CoP knowledge base. Even though these factors are strictly connected with the specific context under analysis, they seem to be rather typical in a public setting, and thus, they represent an interesting starting point for scholars who wish to address this issue in the future.

From the practical point of view, this study provides public managers with a systematic approach and a set of useful suggestions on how to proceed in order to successfully develop and sustain CoP 
activities to improve work practices. Particularly, it underlines the need for managers to pay particular attention to specific contextual factors that could hinder CoP development.

The study is not without limitations. This case study was based on a single organisation with specific practices and contextual factors. The analysis only concerned the operations level; future studies should investigate CoP development initiatives at the tactical and strategic levels. Further studies with a longer study period could also analyse the long-term impacts of CoPs on knowledge sharing and practice improvement. From a PSO perspective, future studies could also focus on how changes in legislation are adopted into the organisational practice with the CoP as an enabler.

In conclusion, PSOs are increasingly expected to improve their productivity, even in situations of continuous budget cuts, which negatively affect service levels. This study demonstrated that implementing a CoP as a KM initiative is an alternative approach to improve performance and should serve as inspiration for longer-term initiatives.

\section{References}

Agrifoglio, R. (2015), Knowledge Preservation Through Community of Practice, Springer International Publishing, Cham, Switzerland.

Akhavan, P., Marzieh, B. and Mirjafari, M. (2015), "Identifying the success factors of communities of practice (CoPs): how do they affect on students to create knowledge", VINE Journal of Information and Knowledge Management Systems, Vol. 45 No. 2, pp. 198-213.

Akkerman, S., Petter, C. and de Laat, M. (2008), "Organising communities-of-practice: facilitating emergence", Journal of Workplace Learning, Vol. 20 No. 6, pp. 383-399.

Aljuwaiber, A. (2016), "Communities of practice as an initiative for knowledge sharing in business organisations: a literature review", Journal of Knowledge Management, Vol. 20 No. 4, pp. 731-758.

Amayah, A.T. (2013), "Determinants of knowledge sharing in a public sector organization", Journal of Knowledge Management, Vol. 17 No. 3, pp. 454-471.

Bate, P. and Robert, G. (2002) "Knowledge management and communities of practice in the private sector: lessons for modernizing the National Health Service in England and Wales", Public Administration, Vol. 80 No. 4, pp. 643-663.

Bolisani, E. and Scarso, E. (2014), "The place of communities of practice in knowledge management studies: a critical review", Journal of Knowledge Management, Vol. 18 No. 2, pp. $366-381$.

Blunk, O. and Prilla, M. (2017), "Supporting communities of practice in public administrations: factors influencing adoption and readiness", In Proceedings of the 8th International Conference on Communities and Technologies, Troyes, France, pp. 36-45.

Bryman, A. and Bell, E. (2011), Business Research Methods, 3rd edn., Oxford University Press, New 
York, NY.

Chu, K.W. (2016), "Beginning a journey of knowledge management in a secondary school", Journal of Knowledge Management, Vol. 20 No. 2, pp. 364-385.

Cirella, G. et al. (2018), "Exploring community of practice in Uganda's public sector: environmental impact assessment case study", Sustainability, Vol. 10 No. 7, p. 2502-2502.

Conklin, J. et al. (2013), "Knowledge brokers in a knowledge network: the case of Seniors Health Research Transfer Network knowledge brokers", Implementation Science, Vol. 8 No. 7, pp.424-441.

Diamond, J. and Rush, L. (2012), "Intra-organisational collaboration in one UK university: potential for change or missed opportunity", International Journal of Public Sector Management, Vol. 25 No. 4, pp. 287-300.

Edwards, K. and Winkel, J. (2018), "A method for effect modifier assessment (EMA) in ergonomic intervention research", Applied Ergonomics, Vol. 72, pp. 113-120.

Gabbay, J. and le May, A. (2004), "Evidence based guidelines or collectively constructed 'mindlines?' Ethnographic study of knowledge management in primary care", British Medical Journal (Clinical Research Edition), Vol. 329 No. 7473, p.1-5.

Gau, W.B. (2013), "Public servants' workplace learning: a reflection on the concept of communities of practice", Quality and Quantity, Vol. 47 No. 3, pp. 1519-1530.

Gillani, S.M.F. et al. (2018), "Specific antecedents of employees ' knowledge sharing behavior", VINE Journal of Information and Knowledge Management Systems, Vol. 48 No. 2, pp. 178-98.

Grimshaw, J. et al. (2005), "Effectiveness and efficiency of guideline dissemination and implementation strategies", International Journal of Technology Assessment in Health Care, Vol. 21 No. 1, pp. 1-352.

Gongla, P., and Rizzuto, C.R. (2001), "Evolving communities of practice: IBM Global Services experience", IBM systems journal, Vol. 40 No 4, pp. 842-862.

Hansen, M.T., Nohria, N. and Thomas, T. (1999), "What's your strategy for managing knowledge?", Harvard Business Review, Vol. 12 No. 3, pp. 139-145.

Hatmaker, D.M., Park, H.H. and Rethemeyer, R.K. (2011), "Learning the ropes: communities of practice and social networks in the public sector", International Public Management Journal, Vol. 14 No. 4, pp. 395-419.

Hislop, D. (2013), Knowledge Management in Organizations - A Critical Introduction, 3rd edn., Oxford University Press, New York, NY.

Huysman, M. (2004), "Communities of practice: facilitating social learning while frustrating organizational learning", in Tsoukas, H. and Mylonopoulos, N. (Eds), Organizations as Knowledge Systems: Knowledge, Learning, and Dynamic Capabilities, Palgrave Macmillan, London, UK, pp. 67-85. 
Iaquinto, B., Ison, R. and Faggian, R. (2011), "Creating communities of practice: scoping purposeful design", Journal of Knowledge Management, Vol. 15 No. 1, pp. 4-21.

Jarvie, W. and Stewart, J. (2018), "Conceptualizing learning in the public sector: the importance of context", International Journal of Public Sector Management, Vol. 31 No. 1, pp. 14-30.

Jassbi, A. et al. (2015), "An empirical investigation for alignment of communities of practice with organization using fuzzy Delphi panel", VINE Journal of Information and Knowledge Management Systems, Vol. 45 No. 3, pp. 322-343.

Jørgensen, C. et al. (2018), "Communities of practice in healthcare: a framework for managing knowledge sharing in operations", Knowledge and Process Management, Vol. 26 No. 2, pp. 152-162.

Lave, J. and Wenger, E. (1991), Situated Learning: Legitimate Peripheral Participation, Cambridge University Press, Cambridge, UK.

Lesser, E.L. and Storck, J. (2001), "Communities of practice and organizational performance", IBM Systems Journal, Vol. 40 No. 4, pp. 831-41.

Li, L.C. et al. (2009), “Evolution of Wenger's concept of community of practice”, Implementation Science, Vol. 4 No. 1, p. 1-11.

Massaro, M., Dumay, J. and Garlatti, A. (2015), "Public sector knowledge management: a structured literature review", Journal of Knowledge Management, Vol. 19 No. 3, pp. 530-558.

McKellar, K.A. et al. (2014), "Evaluating communities of practice and knowledge networks: a systematic scoping review of evaluation frameworks", EcoHealth, Vol. 11 No. 3, pp. 383-399.

Mc Evoy, P. J., Ragab, M. A., \& Arisha, A. (2019). "The effectiveness of knowledge management in the public sector", Knowledge Management Research \& Practice, 17(1), 39-51.

Ng, P.T. and Ang, H.S. (2007), "Managing knowledge through communities of practice: the case of the Singapore Police Force", International Journal of Knowledge Management Studies, Vol. 1 No. 3/4, pp. 356-367.

Nithithanatchinnapat, B., Taylor, J., Joshi, K.D. and Weiss, M.L. (2016), “Organizational communities of practice: review, analysis, and role of information and communications technologies", Journal of Organizational Computing and Electronic Commerce, Vol. 26 No. 4, pp. 307-322.

Nutley, S., Davies, H. and Walter, I. (2002), "Conceptual synthesis 1: learning from the diffusion of innovations", Unpublished manuscript, Research Unit for Research Utilization, University of St. Andrews, St. Andrews, UK.

Orr, J.E. (1996), Talking About Machines: An Ethnography of a Modern Job, Cornell University Press, London.

Pee, L.G. and Kankanhalli, A. (2016), "Interactions among factors influencing knowledge 
management in public-sector organizations: a resource-based view", Government Information Quarterly, Vol. 33 No. 1, pp. 188-199.

Pyrko, I., Dörfler, V. and Eden, C. (2017), "Thinking together: what makes communities of practice work?”, Human Relations, Vol. 70 No. 4, pp. 389-409.

Saldaña, J. (2016), The Coding Manual for Qualitative Researchers, 3rd edn., SAGE Publications, Inc., Thousand Oaks, CA.

Sallán, J.G. et al. (2012), "Review of knowledge creation and management processes through communities of practice in public administration", Procedia - Social and Behavioral Sciences, Vol. 46, pp. 2198-2204.

Salleh, K., Chong, S.C., Ahmad, S.N.S. and Ikhsan, S.O.S.S. (2013), "The extent of influence of learning factors on tacit knowledge sharing among public sector accountants", VINE Journal of Information and Knowledge Management Systems, Vol. 43 No. 4, pp. 424-441.

Sandhu, Singh, M., Jain, K.K. and Ahmad, I.U.K. (2011), "Knowledge sharing among public sector employees: evidence from Malaysia", International Journal of Public Sector Management, Vol. 24 No. 3, pp. 206-226.

Scarso, E., Bolisani, E. and Salvador, L. (2009), "A systematic framework for analysing the critical success factors of communities of practice", Journal of Knowledge Management, Vol. 13 No. 6, pp. 431-447.

Seba, I. and Rowley, J. (2010), "Knowledge management in UK police forces", Journal of knowledge management, Vol. 14 No. 4, pp. 611-626.

Wenger, E. (1998), Communities of Practice: Learning, Meaning and Identity, Cambridge University Press, Cambridge, UK.

Wenger, E. (2010), "Communities of practice and social learning systems: the career of a concept", in Blackmore, C. (Ed.), Social Learning Systems and Communities of Practice, The Open University, Springer, London, pp. 179-198

Wenger, E., Snyder, W.M. and McDermott, R. (2002), Cultivating Communities of Practice: A Guide to Managing Knowledge, Harvard Business School Press, Boston, MA.

Wolf, P., Späth, S. and Haefliger, S. (2011), "Participation in intra-firm communities of practice: a case study from the automotive industry", Journal of Knowledge Management, Vol. 15 No. 1, pp. 22-39.

Yin, R.K. (2017), Case Study Research and Applications: Design and Methods, 6th edn., SAGE Publications, Inc., Thousand Oaks, CA. 